\title{
The Study of the Shuikou's Bridge in Huizhou Ancient Village
}

\author{
Ying Pan ${ }^{1,}$ a,Guoqing $\mathrm{Li}^{2, \mathrm{~b}}$
}

${ }^{1}$ School of Architecture, South China University of Technology; State Key Laboratory of Subtropical Building Science, South China University of Technology, Guangzhou, Guangdong, China

${ }^{2}$ School of Architechture,South China University of Technology,Guangzhou,Guangdong,China a13380056897@163.com, b957138429@qq.com

Keywords: Huizhou; ancient village; shuikou garden; bridge

Abstract. The bridge is one of the main elements of Huizhou ancient village shuikou. It is practical, spiritual, public,even the gateway to the village. On the basis of extensive literature review and field investigation, the history, function, form and image of the shuikou corridor of Huizhou ancient village are analyzed systematically. It follows that the bridge was raised by the villagers and built on the basis of feng shui. It not only adapts to the local natural geography, but also meets the psychological needs of the villagers.

\section{Overview of Shuikou Garden}

Shuikou garden, originated from feng shui, is an important basis on site selection. The shuikou is where water flows out of an area. In the ancient Huizhou area where advocating the feng shui theory to guide the layout of the village location,the design of the shuikou naturally becomes a vital part of the village landscape.

Most of the ancient villages in Huizhou are linked by blood and clan, with the family as the unit. Initial construction of the shuikou is led by the patriarch of the village, with the villagers' co-financing and builting. Ming and Qing Dynasties are the peak period of the development of water gap, which is inseparable with the expansion of the Huizhou merchants [1]. Rich merchants in glory, were eager to rebuild home. However, Huizhou is located in the mountains that lack land and rich merchants gathered in each villages. It's difficult for each family to construct private gardens. Therefore, they chiselled pond, repaired mountain and built a bridge, which provides a shared space of tourism, trade and communication for the villagers.

Mountain, water, forest, building, square and path constitute the six major elements of the landscape of Huizhou shuikou garden [2]. The main building includes: bridge, pavilion,floor, tower, arch and so on. Each village has its own different combination of architecture. Lounge bridge is the most significant component of the whole water gap. If you want to enter the village, you must pass the bridge.

\section{The History of the Shuikou's Bridge}

According to historical records, Huizhou's bridges had already existed during the Northern and Southern Song Dynasties. Chunyuan bridge in Jingde county (formerly known as Pingzheng bridge ), was built in the Northern Song Dynasty Yuanfeng five years (in 1082). Rainbow Bridge in Qinghua town Wuyuan county, was initially built in the Southern Song Dynasty (in 1137). Bridge is 140 meters long, 3 meters wide, with 4 piers and 5 holes, consisting of 11 pavilions. It bocome famous because of the Tang poetry "two water folder mirror, double bridge rainbow". Haoxi Bridge in Wuyuan county and Huanxiu bridge in Chengkan village She county, were both built in the Yuan Dynasty.

Accompanied by the rise of the Ming and Qing merchants, they returned to the village to reshape the village style. As the most important sign of the shuikou garden, corridor also ushered in its historical development climax. A great number of Shuikou's bridges in Huizhou were built at this time. 


\section{The Function of Shuikou's Bridge}

In the ancient village of Huizhou, the corridor acts as a sign of the main outlet momentum, and then supplemented by pavilions, platform, floor, court, tower and so on to increase the tempo, which is the usual way. In addition, the bridge also connects cross-strait traffic, organize water features, and rich landscape level. The bridge makes it possible for the villagers to occupy the river space. Here, they also perceive both external and internal, free and protected. Regardless of feng shui good and bad, corridor has an excellent function both in the entrance sequence of the organization's village and landscape level. Here we will analyze in detail:

Practicability. Huizhou village attaches great importance to the defense of the village. Not only did they regard defense as an important factor in the site selection, but also value construction of villages, which created defensive architecture. A great deal of shuikou is the only village entrance, corridor naturally has a similar defense function, specifically Early shuikou bridge. Such as Wuyuan County Qingyuan Village Bridge, three-story bridge, covers the village tightly. Only through the arch on the bridge could enter the village [3]. With the change of dynasties, the security situation in Huizhou has been improved. Furthermore, with the continuous expansion of modern villages, old shuikou gardens have been located in the village center, which leads to the defense function of bridges has gradually weakened. But the location of bridge revealed that it used to guard the village.

As the junction of the village inside and outside, the traffic of bridge is busiest. There are some mountain villages due to streams in the village meandering circuitous, built more bridges to connect the two sides to facilitate traffic.

Spirituality. The water at the shuikou, as a symbol of wealth, can not be lost easily in feng shui theory. But to stop the river is difficult to achieve, then try to make the water blocked to comfort the psychology. Not every Huizhou settlements have shuikou mountain, so they used the tower, stone tablet and talisman to "suppress evil". For example, Jixi county $\mathrm{Hu}$ village shuikou set the "lion" and "elephant" sculpture to make up the lack of shuikou mountain. There is even a Buddha pillar in the Tongji bridge of Sixi village. This is the protector of hamlet, so that the aura inside won't leak while the evil outside can not come in.

Identity. Some of the public facilities in the village, such as bridges, dams, academies, is a matter of time and money, but these can improve the image of village. This is not only a show off to Huizhou merchants, and the dissemination of culture, but also immortal. It is also a very important reason why Huizhou values public facilities. The bridge built into exquisite corridor, or pavilion, square or combination, become a public space of tastes. Such examples in the mountain villages keep more intact. For example, Qiman village and Taoyuan village, deep in the hinterland of the mountain, both constructed an eye-catching lounge bridge.

The most prominent bridge is Beian village, which is planned thoroughly and designed exquisitely. It is a beautiful combination of windows. Whether it's shape, size or location of the hole takes into account the effect of the appearance. And set exquisite poncho in the window, both sides with carved brace support, even more elegant [4].If not intended to create a village "portal", it will never produce such a noble and graceful effect.

Publicity. In addition to the defense, traffic, the main value of shuikou bridge is the rest, exchanges, tours. In the summer evening, women and farmers stop here, talk and laugh, admire the moon, shade, play chess,so the bridge became a cozy place to gather the villagers.

Huizhou merchants have flourished in the history of China, shuikou corridor is also a good place for traders. Huizhou villages often set up the street along the river, including "water street". With the development in the Ming and Qing Dynasties, many shuikou garden in Huizhou become the commercial node, so the bridge has become a trade space. For instance, Gaoyang bridge on the river connected the shops on both sides. 


\section{Relationship Between Shuikou's Bridge and Village}

Shuikou garden in Huizhou ancient villages is often combined with topography. Architecture and natural elements (mountains, water, forests) blend together, which form a point - line - surface spatial relationship. The bridge is the main element in the streamline. The artificial beauty of the individual building, once integrated into the surroundings, is a natural order to convey. The beauty that we feel is an extension of natural beauty.

Further analysis of "natural order", Huizhou village is an organic whole, then shuikou bridge is naturally combined with the overall background to consider. All things are not isolated in the world, they are interdependent, mutual influence. In this concept of "harmony between man and nature" and the ecological point of view, it requires that village should not exceed the ecological capacity and keep a small change in landscape [5]. The shape and scale of the bridge must be considered across-the-aboard. Constructing corridor helps to drive the activity of the nozzle, thus radiate to the whole village.

Gaoyang Bridge. Xu village Shexian County, a group of buildings of which constitute the most unique attractions, including the bridge, court, square, temple four elements, which are Xu village's iconic facilities. Stone bridge which was the earliest, degenerated in Ming Dynasty, then the villagers rebuilt as before and renamed the Goyang bridge. Existing pavilion on the bridge were built in the Qing Kangxi years. There is also a pavilion on the east side of the bridge, named Daguan pavilion, for overlooking and convening guests. There are three stone archs in the east of the bridge, Wuma arch of wich was originally a wooden arch, and was reconstructed in Chenghua years after the destruction. There was a temple along the river, but no longer exists now. This set of shuikou architectures, which formed by the bridge, temple, and arch, finally the pavilion, constitute the logo group of village. It is not only the traffic hub and rest place for people, but also the pride of the village.

Centipede Bridge. There is a curved bridge at the entrance to the Tangmo village. "S" shaped bridge was erected by the two piers and six feldspars, like a centipede. There is a pavilion along the bridge for a short break before entering the village. Out of the pavilion along the stone road is the fellow Hanlin Square. The stone road along river is a vital path into village and is the scenic spot of the dynamic line with river gurgling, winding. Several bridges across the river enrich the space level. Hills across the creek, connecting people to the village, playing a very good role in guiding scenery. Pavilion, long embankment and jade bridge connect into the lake. The twists and turns divide the lake further, which seems gentle beauty [6]. There are sandalwood, Bauhinia and peach forest originally on the roadside. Bridges, other buildings and streams, hills, trees, together to create a tour space.

Wansong Bridge. Nanping village is located in the south of Yixian county basin. The land is flat and fertile and the water is clear. A stream surrounds the village. Wansong bridge cross the river. The stream in the west side of Wansong bridge has a south diversion, after several twists and turns around a pine forest,and then flow to the East before Qushui garden. There are not only meandering streams, pine forest, bamboo garden, ancient camphor, locust tree, spring and other natural elements, but also stone bridge, trails, Wansong pavilion, Qushui garden, Kuixing floor, Wenchang pavilion, Guanying pavilion and other artificial masonry. A series of hidden cottages are in front of the open country field, followed by the stretch of the Nanping mountains.

Wansong bridge is the starting point of the village, three holes, 40 meters long, 5.3 meters high, 4 meters wide. It has unique fame and culture which is different from the general stone bridge. Most of the buildings in the whole village attractions were built for cultural activities. Because of this strong artistic atmosph, shuikou landscape seems especially distinctive as well.

\section{Conclusion}

Shuikou garden in Huizhou ancient villages is often combined with topography. Architecture and natural elements (mountains, water, forests) blend together. The lounge bridge is one of the basic 
elements of Huizhou ancient shuikou. It is practical, spiritual, public, but also the gateway to the village. It is the main public space for the villagers, and it enhance the cohesion of the whole village as well.

\section{References}

[1] Ming Sun: Huizhou ancient village shuikou landscape construction and interpretation (2010), In Chinese

[2] Yun Zhai: Science and Technology Innovation Herald No. 01(2008), P.122, In Chinese

[3] Yongchun Zhu: Chinese Landscape Architecture No. 05(2015), P.111-114, In Chinese

[4] Chenjin Kan, Zemin Wu: Development of Small Cities \& Towns No. 01(2009), P.63-68, In Chinese

[5] Lei Zhao: Science and Technology of West China No. 01(2008), P.21-22, In Chinese

[6] Guxi Pan : Landscape art of Jiangnan (2001), In Chinese 